\title{
Caring for Pregnant Patients with COVID-19: Practical Tips Getting from Policy to Practice
}

\author{
Viktoriya London, MD ${ }^{1}$ Rodney McLaren Jr., MD ${ }^{1} \quad$ Janet Stein, MD, MS ${ }^{1}$ Fouad Atallah, MD ${ }^{1}$ \\ Nelli Fisher, MD ${ }^{1}$ Shoshana Haberman, MD, PhD ${ }^{1}$ Sandra McCalla, MD ${ }^{1}$ Howard Minkoff, MD ${ }^{1,2}$ \\ ${ }^{1}$ Department of Obstetrics and Gynecology, Maimonides Medical \\ Center, Brooklyn, New York \\ 2 Department of Obstetrics and Gynecology, SUNY Downstate \\ Address for correspondence Rodney McLaren Jr., MD, Department of \\ Obstetrics and Gynecology, Maimonides Medical Center, 967 48th \\ Street, Brooklyn, NY 11219 (e-mail: rmclaren624@gmail.com).
} Medical Center, Brooklyn, New York

Am J Perinatol 2020;37:850-853.

\section{Abstract \\ Keywords \\ - COVID-19 \\ - labor and delivery \\ - novel coronavirus \\ - psychosocial challenges \\ - universal testing}

Novel coronavirus disease 2019 (COVID-19) is a pandemic with most American cases in New York. As an institution residing in a high-prevalence zip code, with over 8,000 births annually, we have cared for over 80 COVID-19-infected pregnant women, and have encountered many challenges in applying new national standards for care. In this article, we review how to change outpatient and inpatient practices, develop, and disseminate new hospital protocols, and we highlight the psychosocial challenges for pregnant patients and their providers.

Key Points

- Novel coronavirus disease 2019 (COVID-19) information rapidly changes.

- Multidisciplinary communication is key.

- This study addresses psychosocial challenges.

A viral infection of novel coronavirus disease 2019 (COVID-19) emerged with initial cases reported from Wuhan, China, in December, 2019.1,2 As of March 11, 2020, COVID-19 had become a pandemic. By April 15, there were1,914,916 confirmed cases worldwide and 605,390 cases with 24,582 deaths in the United States. ${ }^{3,4}$ New York State has the most cases, 201,834 (33.3\% of the total reported cases in United States). ${ }^{4}$

Several organizations have recently promulgated standards for the care of COVID-19-infected pregnant women. ${ }^{5-9}$ While these standards are evidence-based and reasonable, executing them can be challenging. There have been some publications providing guidance for instituting COVID-19 care; however, they covered only a few selected topics (e.g., operating room and second stage of labor). ${ }^{10,11}$ Having now cared for over 80 such women, we can share our experience, highlighting the difficulties in translating policies into practice, and offering practical tips for implementing the new standards into obstetric practice ( - Table 1 ).

\section{Outpatient Practices}

Two aspects of outpatient care needed to be considered: (1) how to change practice to minimize viral exposure of healthy patients and providers, and (2) how to utilize outpatient resources to off-load some of the inpatient burden of taking care of COVID-19 patients.

To address the first point, a system should be implemented to screen all patients by phone for COVID-19-related symptoms and exposure prior to their presentation to perinatal units or outpatient offices. In addition, perinatal unit protocols should be revised to decrease the frequency of ultrasound testing and the visit frequency for high-risk and low-risk patients in outpatient offices, using published guidelines. ${ }^{8,9}$ Using those guidelines, we were able to decrease our ultrasound volume by over $50 \%$. We maintained approximately the normal frequency of contacts with highrisk patients by converting office visits to phone visits. received

April 16, 2020

accepted after revision

April 18, 2020

published online

May 7, 2020
Copyright $\odot 2020$ by Thieme Medical

Publishers, Inc., 333 Seventh Avenue, New York, NY 10001, USA. Tel: +1(212) 760-0888
DOI https://doi.org/ 10.1055/s-0040-1710539. ISSN 0735-1631. 
Table 1 Summary of practical tips

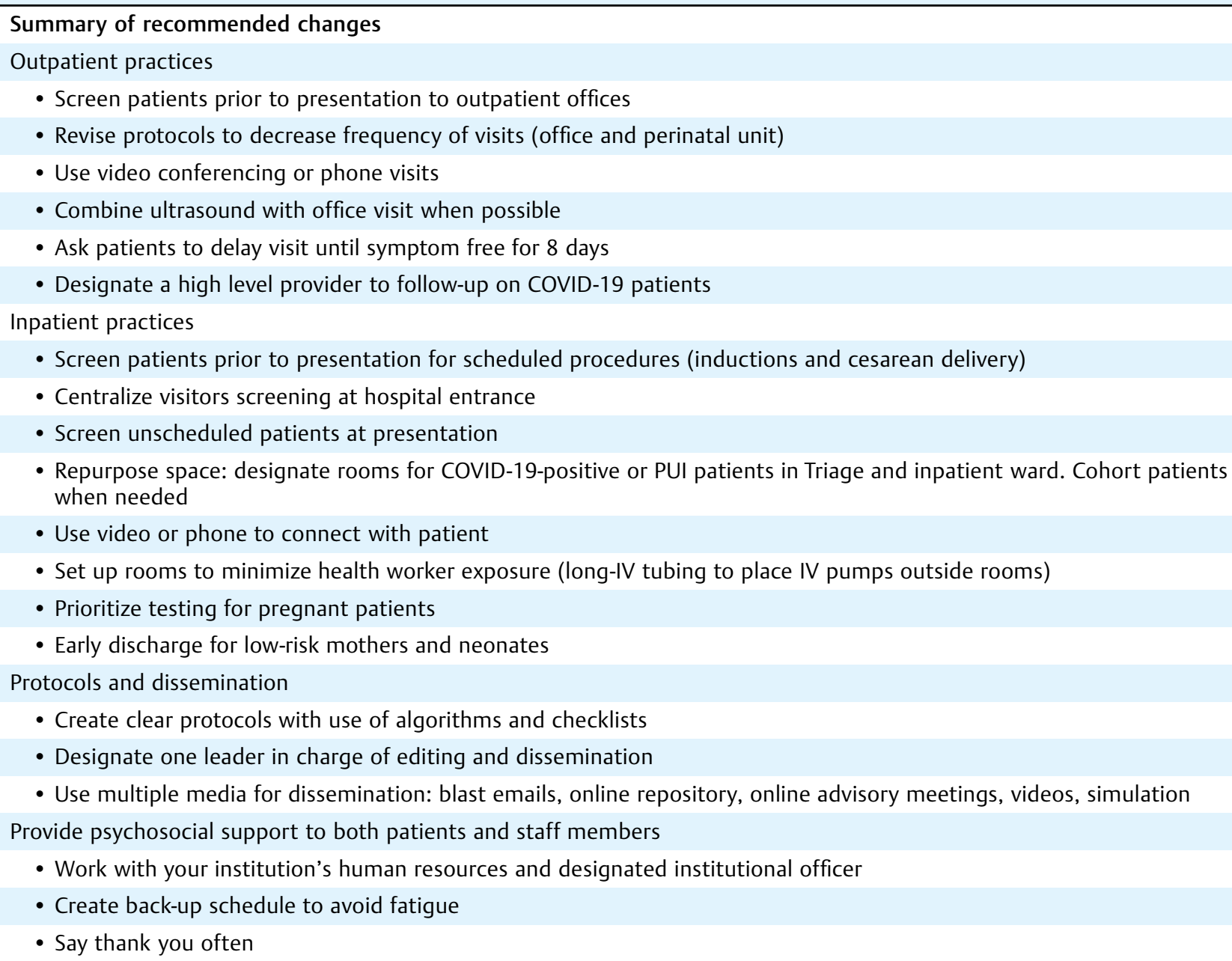

Abbreviations: COVID-19, novel coronavirus disease 2019; IV, intravenous; PUI, persons under investigation.

Each institution should assign a designated COVID-19 provider. To address patients who screen positive for COVID19 symptoms, they are asked to stay home to isolate, and set up a system of outpatient follow-up. The designated practitioner acts as a referral provider for all pregnant COVID-19 patients. That provider maintains a list of patients and performs regular phone visits, with the frequency of calls dependent on patient acuity. Patients should also be given the provider's contact number, which is essential for answering patient questions, and for decreasing the flow of low-acuity patients into inpatient triage areas. If a patient, who was followed on an outpatient basis, needs in-hospital evaluations, either for maternal indications (e.g., shortness of breath) or for fetal monitoring, the designated provider coordinates visits between the patient and the in-patient staff.

\section{Inpatient Practice}

Changes to the inpatient practice can be more challenging. All patients referred to triage, or scheduled for cesarean delivery or induction, should be screened for COVID-19-related symptoms prior to presentation. Hospitals should institute screening at the entrance (with a questionnaire and temperatures) for visitors accompanying patients. Labor and delivery registration staff and nursing must be taught to screen patients at presentation (screening questions in - Fig. 1). Among the 950 patients evaluated in triage, between March 15 and April 15, 2020,81 (8.5\%) screened positive by questionnaire. Of the patients who screened positive, 21 (25.9\%) had no symptoms but did have exposure, 32 (39.5\%) had a cough and no fever, and 28 (34.6\%) had moderate/severe symptoms (e.g., fever or shortness of breath). Fifty-eight (71.6\%) of the patients were confirmed COVID-19 positive by screening through polymerase chain reaction (PCR) of nasopharyngeal swabs. Among the patients who were COVID-19 positive $(n=58), 23$ (39.7\%) had mild symptoms and 23 (39.7\%) had moderate-to-severe symptoms. Among the patients who tested negative for COVID-19 $(n=23)$, nine (39.1\%) had mild symptoms and five (21.7\%) had moderate-to-severe symptoms.

The labor and delivery waiting room may need to be repurposed, removing most chairs to prevent congregation of large groups, or reconfigured to create a closed off patient intake space. Patients who screen positive should immediately be given a mask, have their cell phone number recorded, and be escorted to a designated, isolated COVID-19 triage 
Testing and isolation guidelines for obstetrical patients: edited April 2, 2020

Any pregnant or postpartum patient who presents to L\&D/Triage with obstetrical or medical complaints will be screened for COVID-19 symptoms New Screening Questions:

- Do you have fever or respiratory symptoms (cough, shortness of breath, and chest pain)?

- Have you had contact with a suspected or confirmed case of COVID-19?

- Have you or anyone in your family been tested for COVID-19? If a patient screens positive for COVID-19 by answering yes, she remains a PUI for 2 weeks after resolution of fever/symptoms of the person she was exposed to.

- Depending on the answer you get the following classification (table):

\begin{tabular}{|c|c|c|c|c|c|c|}
\hline \multicolumn{2}{|c|}{$\begin{array}{l}\text { Screening, testing, and } \\
\text { measures }\end{array}$} & $\begin{array}{l}\text { Screen negative (no to } \\
\text { questions } 1 \text { and 2) }\end{array}$ & $\begin{array}{l}\text { Screen positive } \\
\text { Yes to contact only } \\
\text { (question 2) } \\
\text { No symptoms }\end{array}$ & $\begin{array}{l}\text { Screen positive } \\
\text { Mild symptoms (cough, } \\
\text { no fever) }\end{array}$ & $\begin{array}{l}\text { Screen positive } \\
\text { Moderate symptoms } \\
\text { (fever and cough) }\end{array}$ & $\begin{array}{l}\text { Screen positive } \\
\text { Severe symptoms } \\
\text { (chest pain, shortness } \\
\text { of breath, any } \\
\text { desaturation }<95 \% \text { ) }\end{array}$ \\
\hline \multirow{3}{*}{$\begin{array}{l}\text { No } \\
\text { obstetrical } \\
\text { reason for } \\
\text { admission }\end{array}$} & Test & No & $\begin{array}{l}\text { No (except if } \geq 28 \\
\text { weeks, routine) }\end{array}$ & $\begin{array}{l}\text { No (except if } \geq 28 \\
\text { weeks, expedited) }\end{array}$ & $\begin{array}{l}\text { No (except if } \geq 28 \\
\text { weeks, expedited) }\end{array}$ & Yes, expedited \\
\hline & PPE & $\begin{array}{l}\text { Provider: surgical mask } \\
\text { Patient: none }\end{array}$ & $\begin{array}{l}\text { Provider: surgical mask } \\
\text { Patient: surgical mask }\end{array}$ & $\begin{array}{l}\text { Provider: full PPE + N95 } \\
\text { + eye protection } \\
\text { Patient: surgical mask }\end{array}$ & $\begin{array}{l}\text { Provider: full PPE + N95 } \\
\text { + eye protection } \\
\text { Patient: surgical mask }\end{array}$ & $\begin{array}{l}\text { Provider: full PPE + N95 } \\
\text { + eye protection } \\
\text { Patient: surgical mask }\end{array}$ \\
\hline & Disposition & $\begin{array}{l}\text { Discharge with COVID- } \\
19 \text { precautions and } \\
\text { return instructions, no } \\
\text { daily follow-up }\end{array}$ & $\begin{array}{l}\text { Discharge with COVID- } \\
19 \text { precautions and } \\
\text { return Instructions, no } \\
\text { daily follow-up }\end{array}$ & $\begin{array}{l}\text { Discharge with daily } \\
\text { follow-up by phone and } \\
\text { return instructions }\end{array}$ & $\begin{array}{l}\text { Discharge with daily } \\
\text { follow-up by phone and } \\
\text { return instructions }\end{array}$ & Admit \\
\hline \multirow{3}{*}{$\begin{array}{l}\text { Obstetrical } \\
\text { reason for } \\
\text { admission }\end{array}$} & Test & No & Yes, expedited & Yes, expedited & Yes, expedited & Yes, expedited \\
\hline & PPE & $\begin{array}{l}\text { Provider: surgical mask } \\
\text { Patient: none }\end{array}$ & $\begin{array}{l}\text { Provider: full PPE + N95 } \\
\text { + eye protection } \\
\text { Patient: surgical mask }\end{array}$ & $\begin{array}{l}\text { Provider: full PPE + N95 } \\
\text { + eye protection } \\
\text { Patient: surgical mask }\end{array}$ & $\begin{array}{l}\text { Provider: full PPE + N95 } \\
\text { + eye protection } \\
\text { Patient: surgical mask }\end{array}$ & $\begin{array}{l}\text { Provider: full PPE + N95 } \\
\text { + eye protection } \\
\text { Patient: surgical mask }\end{array}$ \\
\hline & Isolation & No & Yes & Yes & Yes & Yes \\
\hline
\end{tabular}

Additional considerations:

Patients discharged home should not get any prescriptions specific to the treatment of COVID (NO Azithromycin or Hydroxychloroquine)

Patients with severe symptoms: if in respiratory distress, call RRT/code 3 if needed or transfer to the ED if no need for a code. Call intensivist when needed.

If the symptoms are moderate, the patient does not need to come to the ED as long as the obstetrician is comfortable in assessing the patient's respiratory status. The provider of record is responsible to maintain phone contact with the patient.

- Inform the patient: If you are COVID positive or screen positive you CANNOT have visitors. If you screen negative, you will be allowed ONE HEALTHY SCREEN NEGATIVE VISITOR in labor. This policy is subject to change at any time for your safety.

Fig. 1 Sample screening and testing algorithm. COVID-19, novel coronavirus disease 2019; ED, emergency department; L\&D, labor and delivery; PPE, personal protective equipment; PUI, persons under investigation; RRT, rapid response team.

room. Nurses and providers should take a patient history over the patient's cell phone prior to entering the room. The setup of the COVID-19 designated triage room should be capable of streaming maternal and fetal monitoring information to screens from outside the room. Personnel from Information and Technology should be involved in planning for the organization of the unit.

If a patient needs admission, she should be transferred to a designated room, which should be set up for phone or overhead communication with the patient, and have a window installed in the door. Intravenous (IV) extension tubing should be utilized to allow the IV pumps to be placed outside the rooms, decreasing nurses' exposure to COVID-19 patients.

As our hospital began to see more and more COVID-19 patients, we became unable to accommodate all of these patients in the designated rooms. If this happens, hospitals should create rooms where COVID-19-positive patients can be cohorted. This can be a labor room that can accommodate multiple patients. An unused gynecological operating room (available because of the suspension of elective surgery) can be used as a recovery room for up to three postpartum/postoperative COVID-19-positive patients. With adequate resources and materials for testing, universal testing of all patients admitted to labor and delivery should be performed with providers wearing personal protective equipment for all patients until the result is available. However, the unavailability of universal COVID-19 testing and/or a long-turnaround time for test results can significantly limit the ability to cohort patients. Strong consideration should be given to prioritizing pregnant patients when allocating testing resources within an institution. The benefits of cohorting include increased safety to the labor floor staff and other patients due to confined exposure, conservation of personal protective equipment (PPE), streamlined care for COVID-19 patients, and the psychosocial benefits of decreased isolation for COVID-19 patients. Cohorting of patients may be unnecessary if the prevalence of coronavirus is low, but should be instituted if and when it increases.

\section{Development of Clinical Protocols and Information Dissemination}

One of the biggest challenges of the pandemic is the constantly evolving flow of clinical information. When we saw our first few COVID19-infected patients, we managed them on a case-by-case basis, with a multidisciplinary approach and extensive consultation by other services such as emergency medicine, infectious disease, internal medicine, and intensive care unit (ICU). If the number of COVID-19 cases remains low, that approach can be maintained. However, the rapid increase in volume and the overwhelmed critical care services made such a model impossible. Instead obstetricians should work with colleagues in other disciplines to create a series of guidelines and protocols that match their institution's needs. It is important to note that due to the decreased 
respiratory reserve in pregnancy and fetal requirements for maternal oxygenation, pregnant patients require different thresholds than the general population for oxygen supplementation and ICU care. As resources become limited, specific allocation of respiratory equipment and ICU care for pregnant patients will be needed. Discussions about these resources should be held early in the course of preparation.

Due to the constantly changing information, protocols should be updated on a regular basis. In our experience, designating one leader in each discipline (nursing, physician, and resident staff) to distribute information can decrease misinformation and insure clear communication among multiple providers.

\section{Psychosocial Challenges}

The COVID-19 pandemic poses unique psychosocial challenges for pregnant patients who are too numerous to be addressed in detail in this paper. The difficulties span all aspects of care including outpatient communication, patient screening, labor management, breastfeeding, and postpartum bonding between the mother and her newborn. The ability for frequent reciprocal communication with patients to mitigate stress is essential, and creating systems for different modes of communication (e.g., phone, e-mail, and text) are helpful.

An unexpected challenge was addressing the patients' and their visitors' reluctance to answer screening questions truthfully due to fear of isolation during the hospitalization and labor. This should prompt strict screening protocols, including mandatory temperature measurement for all visitors, and allowing only one designated visitor for the entire hospitalization. Despite such measures, we continue to experience inadvertent COVID-19 exposure due to lack of universal testing and misinformation obtained during the screening process. Support systems during hospitalizations, such as virtual doulas and easily accessible phone and video connections have the potential to relieve patient anxiety and promote accurate screening.

Maternal and newborn bonding remains a significant challenge. Frequent communication with the parents, providing video streaming from baby cameras in the NICU, educating parents regarding risks of transmission and providing multiple options for newborn nutrition are some useful strategies.

The psychological burdens on providers must also be considered. In addition to the fear of infection, there is the fear of being a "transmitter" to family members. Directly addressing this is a critical component of maintaining morale in the midst of the pandemic. Psychological services should be available to all staff.

\section{Conclusion}

The standards promulgated by American College of Obstetricians and Gynecologists (ACOG) and Society of Maternalfetal Medicine (SMFM) are extremely helpful. Putting them into practice can be challenging. The blueprint for implementation that is presented in this article should help providers and hospitals to plan as the number of cases of COVID-19 increase in the United States.

\section{Conflict of Interest}

None declared.

\section{References}

1 Rasmussen SA, Jamieson DJ. Coronavirus disease 2019 (COVID19) and pregnancy: responding to a rapidly evolving situation. Obstet Gynecol 2020 (e-pub ahead of print). Doi: 10.1097/ AOG.0000000000003873

2 Rasmussen SA, Smulian JC, Lednicky JA, Wen TS, Jamieson DJ. Coronavirus Disease 2019 (COVID-19) and Pregnancy: what obstetricians need to know. Am J Obstet Gynecol 2020 (e-pub ahead of print). Doi: 10.1016/j.ajog.2020.02.017

3 World Health Organization. Coronavirus disease 2019 (COVID19) situation report-86. Available at: https://www.who.int/docs/ default-source/coronaviruse/situation-reports/20200415-sitrep86-covid-19.pdf?sfvrsn=c615ea20_6. Accessed April 15, 2020

4 Centers for Disease Control and Prevention. Cases of coronavirus disease 2019 (COVID-19) in the U.S. Available at: https://www.cdc. gov/coronavirus/2019-ncov/cases-in-us.html. Accessed April 15, 2020

5 Centers for Disease Control and Prevention. Coronavirus disease 2019 (COVID-19): for the healthcare professionals. Available at: https://www.cdc.gov/coronavirus/2019-nCoV/hcp/index.html. Accessed April 9, 2020

6 American College of Obstetricians and Gynecologists. Novel coronavirus 2019 (COVID-19). Available at: https://www.acog.org/clinical/clinical-guidance/practice-advisory/articles/ 2020/03/novel-coronavirus-2019\#. Accessed April 9, 2020

7 Society for Maternal-Fetal Medicine. Coronavirus (COVID-19). Available at: https://www.smfm.org/covid19. Accessed April 9, 2020

8 University of Washington Medicine. UW Medicine COVID-19 Resource Site. Available at: https://covid-19.uwmedicine.org/Pages/ default.aspx. Accessed April 1, 2020

9 Boelig RC, Saccone G, Bellussi F, Berghella V. MFM Guidance for COVID-19. Am J Obstet Gynecol 2020. Doi: 10.1016/j.ajogmf. 2020.100106

10 Gonzalez-Brown VM, Reno J, Lortz H, Fiorini K, Costantine MM. Operating room guide for confirmed or suspected COVID19 pregnant patients requiring cesarean delivery. Am J Perinatol 2020 (e-pub ahead of print). Doi: 10.1055/s-00401709683

11 Palatnik A, McIntosh JJ. Protecting labor and delivery personnel from COVID-19 during the second stage of labor. Am J Perinatol 2020 (e-pub ahead of print). Doi: 10.1055/s-0040-1709689 